\title{
VISUAL SYMPTOMS AMONG NON-PRESBYOPIC VIDEO DISPLAY TERMINAL (VDT) OPERATORS IN OWERRI, NIGERIA
}

BY

MEGWAS*, A. U. AND AGUBOSHIM, R. C.

DEPARTMENT OF OPTOMETRY, FACULTY OF HEALTH SCIENCES, IMO STATE UNIVERSITY, OWERRI, IMO STATE, NIGERIA.

EMAIL: tonymegwas@yahoo.com

*Corresponding author

\begin{abstract}
$\boldsymbol{V}$ isual symptoms appear to be the most frequent and most disturbing of computer associated health problems. This study was aimed at investigating the most prevalent visual symptoms encountered among Video Display Terminal (VDT) users in Owerri municipality prior to presbyopic onset. A total of one hundred and eighty-six (186) respondents, comprising 57 males and 129 females in the age bracket of 17-34years (mean age: 25.83 $44.90 y e a r s)$ were divided into two (2) groups: group A comprises of forty (40) non-VDT users and, group B comprises of one hundred and forty-six(146) VDT users. Each group was investigated, using pre-sampling criteria of visual acuity screening and ocular health assessment, before being handed a well-structured questionnaire, to be filled individually. Data consequently obtained revealed that headache (41.78\%); eyestrain (26.72\%), pain (31.51\%) and lacrimation (19.86\%) were the most prevalent visual symptoms among non-presbyopic, Owerri-based VDT users. A comparative one-tailed statistical analysis using the Z-test (0.05) revealed that VDT usage increases the prevalence of visual symptoms among users $(P>0.05)$. It was also revealed that Owerribased, non-presbyopic VDT operators are exposed to environmental risk factors hazardous to them while working. Consequently, this study suggests that intervention programs aimed at ameliorating these problems and the predisposing factors be introduced and sustained, to forestall the outbreak of a dangerous health problem due to VDT usage.
\end{abstract}

KEYWORDS: Visual symptoms, prevalence, Video Display Terminals, non-presbyope, eyestrain.

\section{INTRODUCTION}

The phenomenal versatility of the computer system has led to the application of computer technology in virtually every aspect of human endeavors. Owing to its ability to perform complex and/or physically hazardous operations at unfathomable speed and dexterity, people from every profession now spend large portions of their work hours in front of the computer monitor.

Video display terminal (VDT), as the basic of the computer system is now a basic feature in many offices and workshops and the trend suggests an astronomic growth in the near future. However, in the event of this rapidly expanding awareness and addiction to computer usage, comes growing concerns on the adverse health effects associated with it. The use of VDTs cut across ages, including children ${ }^{1}$ but the youths seem the worst hit by this 'technological miracle' craze as they constitute the greater percentage of the labor force, with very few of them not having access to computers today ${ }^{2}$. Jargons like 'all-night' and 'all-day' browsing are recurrent dictions today as we embark on research and/or communicative explorations.

Substituting computers for typewriters has introduced into the environment, an extremely complex set of variables which may significantly affect operator performance and comfort ${ }^{3}$. VDTs may potentially affect human health through exposure to electromagnetic emission; ergonomic effects; and stress ${ }^{4}$.These effects are made worse owing to the fact the users do not work according to specified conditions for proper VDT usage such as: eye-to-screen distance of 22-28 inches; viewing angle range of between $15-50^{\circ}$ below eye level ${ }^{5}$, terminals positioned at $90^{\circ}$ angle from unshaded windows or doors, the use of standard anti-glare filters, use of fairly new VDTs whose flicker rates are less than $30 \mathrm{~Hz}$, straight horizontal elbow-tofinger line, proper illumination(45-65FC), straight back-neck alignment to mention but a few.

This study, as one of those health-computer investigations is made more significant when it is realized that $70-75 \%$ of VDT-associated health problems are eye and vision problems ${ }^{6,7}$, thus necessitating the need for a shift of emphasis towards oculo-visual-computer related studies for eye care professionals because vision and the environment defines and emphasizes the importance of environmental/occupational optometry for the Optometrist providing primary care $^{8}$.

\section{RESEARCH METHODOLOGY}

The study was an open, prospective investigation, carried out within Owerri Municipal area of Imo State, Nigeria, in which a total of one hundred and eighty-six (186) healthy individuals, 
aged between 17 and 34 years (mean age: $25.83 \pm 4.90$ years) were isolated from a presampling population of about two hundred and fifty (250) persons. The pre-sampling criteria involved oculo-visual examination and historytaking, to ascertain their visual status and rule out pathologic interference with findings.

Presbyopic subjects were excluded, to avoid exaggeration of findings as some of the anticipated symptoms were also associated with uncorrected presbyopia. Instruments employed include visual acuity charts, pen lights, ophthalmoscopes, and questionnaires. Since subjects were not given full permission to exempt from work, they participated within the confines of their workplaces, thus affording the investigators the opportunity of objectively assessing the workplaces and ergonomic factors inherent thereof, especially for the VDT users.

Aside their oculo-visual and physiologic status, group B respondents were drawn from only those who operate VDTs for a minimum of 4 hours daily or 10 hours weekly while group A respondents comprises those who either do not use VDTs at all or use it sparingly. Group B respondents included bankers, commercial operators, secretarial staff, private VDT users while group A respondents included teachers, traders, civil servants, businessmen, drivers, students, among others.

Consequently, those who passed these criteria were each given a questionnaire peculiar to his/her group to fill out. The questionnaire for group B respondents was structured such that questions 1-3 investigated respondent's characteristics: sex, age and occupation; questions 4-7 probed respondent's relationship with VDTs in terms of period of usage, contact hours, breaks and so on; questions 8-11 dealt with respondent's feeling, with respect to VDT use and visual health; question 12-17 assessed intervention program(s) employed to ameliorate the identified visual symptoms and the relevance of such program(s) and questions 18-20 focused on ergonomic factors capable of affecting respondent's comfort while using VDTs and possible etiology of identified visual symptoms. The questionnaire for group A respondents assessed their characteristics and relationship with VDTs.

\section{RESULTS}

Findings revealed that the highest percentage of VDT users $(36.30 \%)$ was aged between 29 and 34 years (table 1), with most operators being commercial users (34.25\%) and bankers (32.19\%). Respondents who had used VDTs for not more than 5years constituted $89.73 \%$ while $41.78 \%$ of the respondents work for between 6 and 10 hours daily. $68.50 \%$ of respondents go on break just once, with such breaks lasting less than 10minutes for $63.01 \%$ of the respondents (tables $2 \& 3$ ).

Majority (89.73\%) affirmed, when questioned closed-endedly if they believe that visual problems could arise due to VDT usage, with a slightly lesser percentage $(78.77 \%)$ actually having visual problems in which they indicted VDT usage. Some $(10.96 \%)$ were not sure of such association. Headache $(41.78 \%)$, pain $(31.51 \%)$, eyestrain $(26.72 \%)$ and watery eyes (excessive lacrimation; $19.86 \%$ ) were the most frequent visual symptoms associated with VDT usage (table 4), occurring equally more during work and both during and after work (31.51\%). Among those believing VDT usage could create visual problems, $63.01 \%$ didn't bother seeking any professional assistance though majority of the general respondents $(73.29 \%)$ acknowledged having access to protective equipment.

For those who wear spectacles while working were $10.27 \% ; 53.33 \%$ of these spectacles contained powered lenses, with majority $(75.0 \%)$ of these lenses prescribed by qualified eye care specialists yet, none of the respondents feels relieved of his/her visual symptoms despite the use of spectacles.

Ergonomic factors indicated include screen glare and improper illumination experienced by $58.22 \%$ and $52.74 \%$ of respondents, respectively. This percentage $(47.26 \%)$ of the respondents is not aware of the specified conditions for proper VDT usage (table 5).

\section{DISCUSSION}

The dominance of female respondents as compared to male concur with reports from other computer-health related studies ${ }^{9}$, probably because men are engaged more in physically-challenging occupations (driving, business ventures to mention but a few), leaving less-challenging occupations (VDT operations, teaching and others) to the female folks.

The age group 29-34yrs was more dominant among the age groups studied just as they are in the wider labor market. Commercial operators $(34.25 \%)$ and bankers $(32.19 \%)$ are the major users of VDTs in Owerri, owing to the fact that Owerri, having a civil service dominated workforce and a litany of education institutions, generate a high volume of paper work and so require business centers to service them. The ICT revolution in the banking sector is also a precursor in this regard. Also of note is the fact that this transit from manual to VDT operations happened within the last10 years, a notable deviation when compared with reports from other parts of the world $^{10}$. Most operators work for between 5 and 10 hours daily (41.78\%) and above 10 hours (36.99\%; see table 2), thereby predisposing them to computer-related health hazards, which co-relate with length of daily contact ${ }^{11}$. 
To aggravate their case, majority of these operators $(68.50 \%)$ take breaks only once, with such lasting barely 10 minutes for $63.01 \%$ (as shown in table 3 ) of the respondents, as their employers stretch them for maximum output and increased revenue. A detailed look at the findings revealed that $60.0 \%$ of those who reported eyestrain also reported headache, implicating eyestrain as a common precursor of headaches occurring when or after performing visuallydemanding tasks ${ }^{12}$.

Though oral evidence by some respondents with good memory ability suggest the absence of these symptoms prior to VDT usage, just few (26.72\%) actually sought professional opinion or assistance, in alignment with the general behavior of the populace who seek medical/professional aid only on emergency basis, though it may be argued that their long work schedule is a serious handicap to assessing medical assistance, not forgetting the economic realities.

Many of the respondents admitted using protective equipment, but the researchers noticed that only glass screen shields were being used at most of these workplaces as devices such as VDT lenses were not provided. Of all those who wear spectacle, while at work, none obtained relief with their spectacles lending credence to the fact that eyeglasses and contact lenses prescribed for general use may not be adequate for VDT work ${ }^{13}$.

Respondents' report of screen glare $(58.22 \%)$ and poor illumination $(52.74 \%)$ concur with results of previous survey ${ }^{14,15}$, indicating need for special lens designs, lens powers and coating needed for maximal visibility and comfort while using VDTs. That $47.26 \%$ of the respondents admitted not being aware of the proper ergonomic conditions for VDT operations, and $21.23 \%$ reported not applying them while working, points to the fact that while we acknowledge that VDTs could enhance efficiency, we tend to ignore the specified ergonomic standards for optimal efficiency, or as noted by Asonye ${ }^{9}$, this finding may portray our perceived infallibility of western products.

Overall results were consistent with those of previous researchers with the insignificant differences likely to have arisen from environmental influences on operators' health and the inability of some of the respondents to actually identify and describe some of these visual symptoms.

Professionals should enlighten the public more on the specified conditions for proper VDT use as well as offer quality and specialized care to VDT users to ameliorate their usual problems and forestall computer-health related syndromes.

\section{REFERENCES}

1. United States' Department for Labor and Administration (1998): Video Display Terminal and the Labor Force, 13(1); 2-7.

2. Verma, S. B. (2001): Computer and Vision. J. Postgrad. Med, 47: 119-20.

3. Miller, S. C. (1984): Meeting the eye care needs of Video Display Operator. J. Am. Optom. Assoc, 65 (8):611-8.

4. Lum, R. R. (2005): VDT Hazards. The Body Electronics-2. John Wiley Inc. California, pp56.

5. Solorzano, S. E. (1999): Effects of vertical viewing angle and eye blink rate during computer work. Int. J. Ind. Ergonomics, 23:104-7.

6. Wolff, A. C. (1997): Eyestrain and VDT use. Wiley-Liss Inc, New York, pp2-8.

7. Sheedy, J. E. (1992): Vision Problems at Video Display Terminals: A Survey of Optometrists. J. Am. Optom. Assoc, 63 (10): 687-92.

8. Pitts, D. C. and Kleinstein, R. N. (1991): Environmental Vision. John Wiley and Sons Ltd, New York, pp13-14.
9. Asonye, C. C. and Achoga, O. G. (2002): Visual Hazards Associated with Video Display Terminals (VDT) operations in Nigeria. Optoboard, 2(1): 18-25.

10. Breysee, P. N. (1994): VDTs and their emissions- An Overview: J. Radiation Prot. Australia, 12: 84-7.

11. Dainoff, M. J., Happ, A. and Crane, P. (1981): Visual Fatigue and Occupational stress in VDT operators. Human Factors. 23: 431-8.

12. Dain, S. J., McCarthy, A. K. and Chan-Ling, T. (1988): Symptoms in VDU operators. Am. J. Optom. Physiol.Optics. 65: 162-7.

13. Daum, K. M. (1988): Symptoms in Video Display Terminal Operators and the presence of small refractive errors. J. Am. Optom. Assoc, 59 (9): 691-8.

14. Gobba, F. M., Borglia, A., Sarti, R., Luberto, F. and Cavalleri, A. (1987): Ergonomics and VDT- induced symptoms. Int. J. HumanComput. Interaction. 11(2): 109-35.

15. Murch, G. (1982): How visible is your display? Electro-optical system Design. McGraw Hill Book Company, Ltd, New York, pp11-24. 
TABLE 1: AGE CHARACTERISTICS OF RESPONDENTS.

\begin{tabular}{|l|l|l|}
\hline Age (years) & Number of respondents & Percentage (\%) \\
\hline $17-22$ & 45 & 30.82 \\
$23-28$ & 48 & 32.88 \\
$29-34$ & 53 & 36.30 \\
Total & 146 & 100.0 \\
\hline
\end{tabular}

TABLE 2: DAILY CONTACT HOURS WITH VDT

\begin{tabular}{|l|c|c|}
\hline Contact hours & Respondents & Percentage (\%) \\
\hline$<1$ & 15 & 10.27 \\
$1-5$ & 16 & 10.96 \\
$6-10$ & 61 & 41.78 \\
$>10$ & 54 & 36.99 \\
Total & 146 & 100.00 \\
\hline
\end{tabular}

TABLE 3: FREQUENCY OF BREAK WHILE WORKING WITH VDTS

\begin{tabular}{|l|c|c|}
\hline Number of times & Respondents & Percentage (\%) \\
\hline 1 & 100 & 68.50 \\
2 & 23 & 15.75 \\
3 and above & 23 & 15.75 \\
Total & 146 & 100.00 \\
\hline
\end{tabular}

TABLE 4: TYPE OF VISUAL SYMPTOMS EXPERIENCED.

\begin{tabular}{|l|c|c|c|}
\hline Symptom & Number of respondents & VDT users (\%) & Non-VDT users (\%) \\
\hline Eyestrain & 39 & 26.72 & 16.03 \\
Headache & 61 & 41.78 & 25.07 \\
Pain & 31.51 & 18.91 \\
Eyeache & 13 & 8.90 & 5.34 \\
Blurred vision & 16 & 10.96 & 6.58 \\
Sandy feelings & 0 & 0 & 7.93 \\
Itching & 8 & 5.48 & 3.29 \\
Watery eyes & 29 & 19.86 & 11.92 \\
Double vision & 12 & 8.22 & 4.93 \\
Total & $* 146$ & $* 100.00$ & $* 100.00$ \\
\hline
\end{tabular}

* Excess is due to multiple responses.

TABLE 5: WORKING WITH SPECIFIED CONDITIONS FOR PROPER VDT USAGE

\begin{tabular}{|l|c|c|}
\hline Response & Number of respondents & Percentage (\%) \\
\hline Yes & 46 & 31.51 \\
No & 31 & 21.23 \\
Not aware of the conditions & 69 & 47.26 \\
Total & 146 & 100.00 \\
\hline
\end{tabular}

